\title{
Makna simbolik gerak tari halibambang
}

\author{
Susi Wendhaningsih', Dwiyana Habsary² \\ Program Studi Pendidikan Tari, FKIP, Universitas Lampung \\ Coorespondence: susi.wendhaningsih@fkip.unila.ac.id
}

\begin{abstract}
This thesis explores the significance of the symbols in the Halibambang dance. These concepts can be traced back to the dance gestures, costumes and assets of the Halibambang dance.The study review focuses on the sense of motion and is related to the principles held by the people of Lampung. The approach used in this research is ethnocoreology. The Halibambang dance is one of the many dances that originate in the Saibatin tradition. It's a dance that's performed in groups. This dance is performed by the woman, and this dance represents the nature of the butterflies. The concept that can be studied apart from the name and the movement of the dance. Results have shown that the sense of the Halibambang. The results showed that the sense of the Halibambang dance movement describes the behavior of people of Lampung, and the movements used also reflect the livelihoods of the Saibatin people.
\end{abstract}

Keywords: Meaning of Symbolic, Dance Movement, Halibambang Dance

\begin{abstract}
Abstrak
Penelitian ini mengkaji makna yang terkandung dalam simbol-simbol yang ada pada tarian halibambang. Makna-makna tersebut dapat ditelusuri dari gerak tari, kostum, serta properti yang terdapat pada tari halibambang. Analisis penelitian berfokus pada makna gerak serta dikaitkan dengan nilai-nilai yang dipegang masyarakat Lampung. Penelitian etnokoreologi ini dilakukan pada masyarakat adat Saibatin. Tari halibambang merupakan salah satu dari sekian banyak tarian yang berasal dari adat Saibatin. Tarian ini merupakan tarian yang ditarikan secara berkelompok. Tarian ini dilakukan oleh putri, tarian ini menggambarkan tentang perilaku kupu-kupu. Makna yang dapat dikaji selain dari nama tarian adalah gerak-gerak yang terdapat dalam tarian. Hasil penelitian menunjukkan makna gerak tari halibambang menggambarkan perilaku masyarakat Lampung, gerak yang terkandung dalam tarian juga menggambarkan mata pencaharian masyarakat Saibatin.
\end{abstract}

Kata kunci: Makna Simbolik, Gerak Tari, Tari halibambang 


\section{Pendahuluan}

Lampung memiliki banyak seni tari tradisonal yang mengakar kuat di masyarakat. Di setiap wilayah hampir memiliki ciri khas seni tersendiri, salah satunya adalah tari. Sebagai contoh tari melinting, tari piring dua belas dan tari halibambang. Dari berbagai tari tersebut ada yang berfungsi sebagai tari persembahan dengan identitas yang kuat (Habsary, 2017), ada juga yang hanya berfungsi sebagai hiburan. Tari halibambang adalah salah satu jenis tari tradisional Lampung yang telah mengalami pergeseran fungsi mulai dari bagian upacara adat Lampung dan menjadi hiburan di berbagai acara. Tari halibambang merupakan sebuah tarian adat yang berasal dari Sekala Brak Kabupaten Lampung Barat, sebagian besar penduduk di daerah tersebut merupakan marga Saibatin. Marga Saibatin dalam silsilah adat di Provinsi Lampung menempati kedudukan dan posisi penting, karena wilayah Skala Brak banyak diakui sebagai suatu wilayah yang memiliki peradaban yang sangat kompleks dan terwariskan turun temurun.

Tari Halibambang mengandung dua definisi arti yakni hali bermakna seperti, bagaikan, sedangkan bambang berarti kupu-kupu. Secara keseluruhan tari halibambang dimaknai sebagai gerakan estetis (tari) yang menggambarkan kupu-kupu yang sedang berterbangan. Kupu-kupu mengibas-ngibas sayapnya di alam yang bebas, dan berayun-ayun di tepian bunga. Tari halibambang adalah simbol kebesaran, estetika, dan kesopanan gadis dan putri dalam menyapa tamu yang dihormati. Sebagaimana tari tradisional Lampung lainnya, tari halibambang awal mulanya merupakan tarian khusus yang ditarikan dalam acara adat Lampung Saibatin. Tarian ini biasanya digunakan secara tertutup dan terbatas hanya pada saat acara nyambai adat Lampung. berdasarkan perkambangannya tari halibambang dapat dipentasakan ditempat terbuka, baik dalam acara penyabutan tamu, pesta pernikahan, pesta rakyat, maupun pesta adat. Meskipun begitu tari halibambang tetap memegang standar aturan-aturan baku dalam tariannya, aturan baku ini dahulu terus diwariskan turun menurun. Tari halibambang juga tidak lagi membatasi penari dari kalangan keluarga Lampung Sekala Brak saja, saat ini masyarakat biasa dapat menarikan tari halibambang. Perubahan atau transformasi tari adalah hal yang lumrah terjadi. Misalnya perubahan tari tradisi menjadi tari kreasi (Hidayatullah \& Bulan, 2017).

Selain makna fisik yang ada dalam tubuh tari halibambang juga terdapat makna simbolik lainnya yang menarik untuk diteliti. Simbol adalah manifestasi tindak-tanduk manusia melalui kebudayaan. Simbol memiliki makna yang berbeda, sehingga memerlukan penafsiran tertentu untuk memahaminya. Artinya, simbol dapat berupa sistem pengetahuan yang digunakan untuk berkomunikasi. Simbol dalam kehidupan masyarakat dapat berupa nilai atau falsafah hidup yang masih dipegang. Simbol adalah ciri bahwa manusia berpikir, merasa, dan berperilaku (Cassirer, 1944). Melalui simbol manusia mengenal halhal baru dan mulai menginterpretasikannya. Berbagai hal baru ditangkap 
manusia melalui perantara simbol. Simbol dapat berupa fisik yang bersifat lahiriah, sedangkan makna adalah hal yang tersembunyi di balik simbol. Sebagai makhluk budaya, kehidupan manusia diwarnai dengan simbol-simbol (Endraswara, 2003). Sedangkan White (1949) menyatakan bahwa simbol merupakan sesuatu yang di dalamnya memiliki nilai-nilai yang digunakan dalam kehidupan. Dengan demikian nilai-nilai dalam tari halibambang seutuhnya dapat digunakan untuk mempelajari kehidupan dan perilaku masyarakat pendukungnya.

Makna dan simbol keduanya adalah dua hal yang tidak terpisahkan. Tindakan manusia adalah penyederhanaan dari simbol, oleh karena itu masih perlu ditelusuri maknanya. Karena, umumnya sesuatu yang memiliki makna merupakan salah satu unsur komunikasi. Jazuli (2001) menjelaskan jika simbol yang buat oleh manusia untuk kepentingan komunikasi; makna dari simbol bisa didapat dari tanda atau gerakan (tari). Sama hal nya dengan tari tradisional lainnya, tari halibambang merupakan salah satu tarian yang ber-genre 'sembah' dan dalam setiap unsur yang terkandung di dalamnya terdapat makna simbolik. Berbagai aspek tari meliputi gerak, iringan, hingga kostum adalah manifestasi dari makna simbolik.

Penelitian tari tradisional Lampung sebelumnya mengulas tentang simbol dan makna tari Melinting (Prabowo, Imron, \& Susanto, 2018), bentuk penyajian tari bedana (Yustika \& Bisri, 2017), ragam gerak tari sigeh penguten (Azzahrah, 2017), dan tari kipas nyambai bebai (Rahmadona, Daryanti, \& Kurniawan, 2015); dari segi properti tari ini memiliki kesamaan. Berdasarkan penelusuran penelitian sebelumnya, belum ada analisis makna simbolik tentang tari halibambang. Kajian makna merupakan hal yang sangat vital dalam konteks analisis koreografi. Istilah makna simbolik diperkenalkan oleh Geertz berkaitan dengan penjelasan makna yang mendalam (Kusumawardani, 2013).

\section{Metode}

Penelitian etnokoreologi ini menggunakan metode pemaparan deskriptif. Metode deskriptif bertujuan menggambarkan objek penelitian secara natural. Metode deskriptif dalam penelitian ini berfungsi mengetahui dan mendeskripsikan bentuk gerak tari halibambang dan makna gerak tari halibambang. Data-data yang diperlukan untuk menjawab bagaimana kedua masalah tersebut, maka diperlukan kajian yang lebih mendalam. Pendekatan etnokoreologi digunakan untuk membedah data dari sudut pandang etnis. Sebagai mana dijelaskan Narawati (2013) bahwa etnokoreologi mencakup batasan aspek tekstual dan kontekstual.

Data penelitian dikumpulkan dengan metode multi-teknik. Mulai dari pengumpulan materi, bahasa dan tindakan yang berkaitan dengan tari halibambang di Bandar Lampung. Materi yang dimaksudkan adalah sesuatu yang berwujud tulisan tentang tari halibambang. Bahasa atau kata-kata dan 
tindakan merupakan sumber data utama yang bersifat pengamatan dan wawancara berupa melihat, mendengar, bertanya kepada narasumber, pelatih dan anggota. Sumber data ini dapat dicatat melalui catatan tertulis atau melalui pengambilan foto, rekaman suara dan video visual recocder saat pementasan dan latihan. Ada bermacam-macam materi berupa sumber data kualitatif yang digunakan.

\section{Observasi}

Pengumpulan data melalui observasi dilakukan untuk mengetahui secara langsung apa yang terjadi dilapangan. Obervasi menangkap data tentang tentang makna simbolik gerak tari halibambang yang berkembang di Bandar Lampung. Dengan mengamati ragam gerak tari, musik, pola lantai, rias dan busana serta properti yang digunakan. Penyajian ini diabadikan dengan cara pemotretan dan juga rekaman secara audio visual. Hasil pendokumentasian tersebut digunakan sebagai data primer. Pada tahap ini, peneliti juga ikut terlibat langsung dan mempelajari gerak-gerak tari halibambang yang terdapat di Taman Budaya Provinsi Lampung, khususnya di daerah yang menggunakan tari halibambang dalam acara-acaranya. Pencarian data tari halibambang di Bandar Lampung khususnya di Taman Budaya dilakukkan sesering mungkin untuk mendapat data yang lebih objektif. Tujuannya untuk meningkatkan keajegan pengamatan sebagaimana dikatakan oleh Moleong (2017). Hal ini juga dilakukan untuk memperoleh data-data yang akurat dan memiliki tingkat keabsahan yang tinggi.

\section{Wawancara}

Data-data yang diproleh dari narasumber, penting untuk dicatat dan dikaji secara mendalam. Penelusuran data tari halibambang yang berkembang saat ini, lebih banyak menggunakan teknik wawancara. Teknik wawancara tidak terstruktur digunakan dan berfokus pada garis besar permasalahan yang akan ditanyakan mengenai gerak tari dan maknanya. Pertanyaan biasanya tidak disusun terlebih dahulu, tetapi pertanyaan akan disesuaikan dengan keadaan dan ciri unik responden (Moleong, 2017). Narasumber yang dipilih adalah yang mengetahi secara pasti dan terlibat langsung dalam kegiatan, serta wawancara dengan beberapa narasumber yang dianggap penting dalam kajian ini. Hasil yang diperoleh data informasi tentang tari halibambang sesuai dengan apa yang ditanyakan, dokumentasi gambar, rekaman hasil wawancara dan data pendukung lainnya.

\section{Dokumentasi}

Pengumpulan data dilakukan dengan pengumpulan foto-foto dan rekaman audio visual. Data-data tersebut dipergunakan untuk memperkuat bahwa proses penelitian benar-benar telah dilakukan. Selain itu data dokumentasi juga berupa 
data hasil wawancara yang berupa catatan dan rekaman, serta foto-foto dan gambar yang berkaitan dengan tari halibambang.

\section{Studi pustaka}

Penelaahan kepustakaan merupakan studi awal, guna mendapatkan informasi secara tertulis dengan melakukan pengump[ulan dan mempelajari beberapa referensi. Referensi dapat diperoleh dari data-data tertulis berupa buku-buku, laporan penelitian, artikel, manuskrip, majalah dan surat kabar yang berkaitan dengan tari halibambang dan beberapa buku yang menunjang untuk penelitian ini. Selain itu dilakukan juga tinjauan pustaka melalui penelitian berupa tesis, disertasi dan publikasi ilmiah lainnya.

Hasil pengamatan yang telah diperoleh, yang dimulai dari pengumpulan data, yaitu mengidentifikasi makna simbolik dari masing-masing unsur dalam tari halibambang pada masa awal hingga makna simbolik gerak tari halibambang yang berkembang saat ini. Unsur-unsur yang dilihat yakni meliputi ragam gerak tari halibambang dan pola lantai yang digunakan, sedangkan data penguat dari analisis makna simbolik pada tari halibambang dilihat juga dari elemen iringan musik, serta kostum yang digunakan. Proses analisis data menggunakan model Miles \& Huberman (1994) dengan tahapan: pengumpulan data, reduksi data, klarifikasi, deskripsi, penyimpulan data, dan menginterpretasi data.

\section{Hasil dan pembahasan}

\section{Gerak ghubuh gakhang}

Unsur-unsur gerak yang menunjang gerak ghubuh gakhang adalah gerak kaki, gerak lengan dan gerak torso. Seluruh unsur tersebut yang merupakan bagian dari gerak ghubuh gakhang. Gerak ghubuh gakhang pada tari halibambang merupakan gerak berpindah tempat. Gerak ghubuh gakhang ini dapat juga ditemui pada tari Sigeh Penguten. Uraian tentang makna yang terkandung pada tari gerak ghubuh gakhang pada tari sigeh penguten telah dipaparkan dalam sebuah disertasi yang ditulis oleh Habsary (2017). Dalam penelitian tersebut, ghubuh gakhang memiliki arti rak di dapur yang roboh atau dapur yang roboh. Gerak ini juga menggambarkan tentang tanggung jawab. Gambaran tentang tanggung jawab seseorang dalam menyelesaikan suatu pekerjaan dan masalah. 


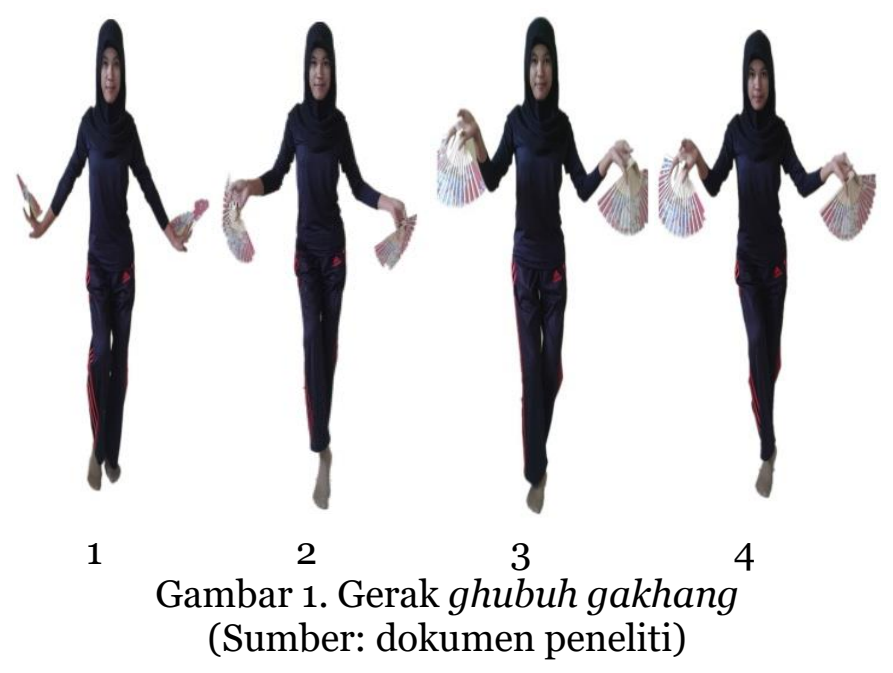

\section{Tolak tebeng}

Gerak tolak tebeng merupakan gerak yang terdapat dalam tari sigeh penguten. Gerak ini sebagaimana dipaparkan oleh Habsary (2017) jika diterjemahkan dalam bahasa Indonesia adalah menolak atau mendorong dengan lurus. Gerak ini mengandung makna ketabahan dalam menghadapi sesuatu. Gerak tolak tebeng merupakan gerak yang disajikan di awal tarian. Hal ini menunjukkan bahwa ketabahan diutamakan dalam menghadapi segala permasalahan yang dihadapi.

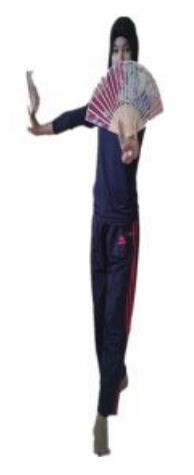

1

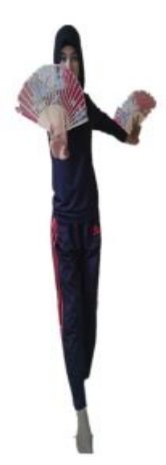

2

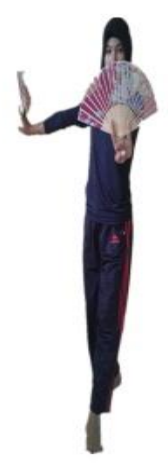

3

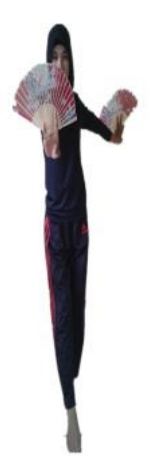

4

Gambar 2. Gerak tolak tebeng

(Sumber: dokumen peneliti)

\section{Jong silo ratu}

Jong Silo Ratu merupakan gerak yang juga bagian dari tari sigeh penguten. Kata jong berasal dari kata 'mejong', jika diartikan dalam bahasa Indonesia adalah duduk. Sikap ini merupakan gambaran sikap duduk yang dapat diterima di Budaya Lampung. Nilai yang terkandung dalam sikap ini adalah senantiasa 
menjaga sikap dalam kondisi dan situasi apapun. Sikap yang senantiasa menjaga dan tahu atau pandai menempatkan diri dalam kondisi apapun dapat membawa seseorang sukses dalam hubungan sosial. Hubungan sosial merupakan sesuatu yang penting untuk dijaga dalam budaya Lampung.

\section{Gerak melayang}

Gerak melayang dalam tari halibambang bisa dibilang merupakan salah satu gerak yang sering muncul. Gerak ini menggambarkan gerak terbang. Hal ini dikarenakan, selain sikap yang merentangkan kedua lengan, gerak pergelangan lengan menunjukkan gerak melayang yang menggepakkan sayap. Gerak melayang biasanya dilakukan sambil berpindah tempat. Pada gambar di atas, gerak melayang dilakukan dengan penyangga jong cengengik yang kemudian diikuti dengan gerak naik dan turun yang menggunakan penyangga sebagai penggeraknya. Gerak melayang sendiri selain menggambarkan kondisi terbang, mengandung arti pula yaitu ketelitian. Sikap yang teliti sangat diperlukan dalam berbagai hal terutama dalam mengerjakan sesuatu atau mengamati sesuatu. Ketelitian akan membuat seseorang melakukan pekerjaan tanpa harus mengulanginya kembali karena ada yang terlewatkan.

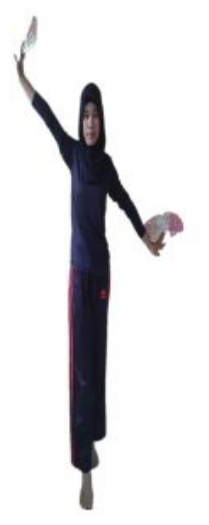

1

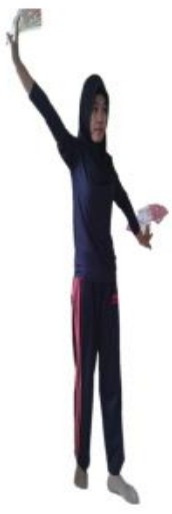

2

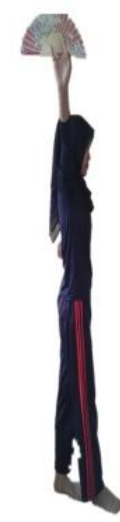

3

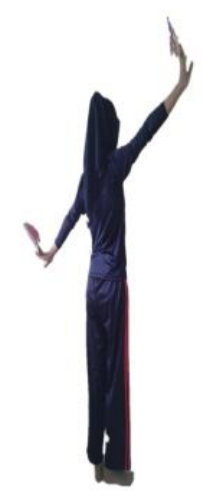

4

Gambar 3. Gerak melayang

(Sumber: dokumen peneliti)

\section{Gerak timbangan}

Gerak Timbangan merupakan grakan yang senantiasa mengubah tinggi lengan. Jika dimaknai secara bahasa, kata timbangan memiliki lima arti. Arti tersebut adalah sebagai berikut. Pertama timbangan berarti imbangan; timbalan; bandingan: bukan timbangannya melawan dia; timbangan badan (nyawa), belahan jiwa (kekasih, istri atau suami). Arti kedua timbangan berarti alat untuk menimbang (seperti neraca, kati): timbangan lima kilogram, alat untuk menimbang maksimum lima kilogram. Arti ketiga timbangan berarti pendapatan menimbang. Arti keempat timbangan berarti pendapat (tentang baik buruk dan sebagainya); putusan (yang diuraikan sebagai nasihat dan 
sebgainya): bagaimana timbanganmu; terserah pada timbangan-mu sendiri; dia diminta supaya memberikan timbangan. Arti kelima timbangan berarti batu timbang. Berdasarkan arti yang diuraikan diatas, kata 'timbangan' dalam aplikasi kehidupan yang diletakkan dalam tari halibambang menunjukkan perlunya berbagai pertimbangan dalam mengambil keputusan dan bersikap. Hal ini akan membuat seseorang selamat dalam menjalani hidup, karena segala sesuatu, baik sikap maupun perkataan senantiasa dipertimbangkan terlebih dahulu sebelum dilakukan.

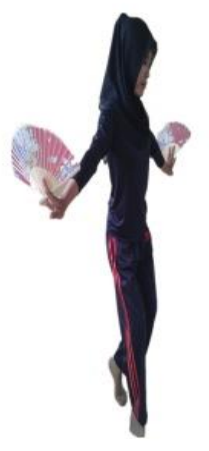

1

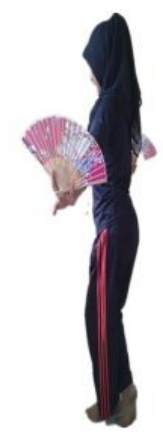

5

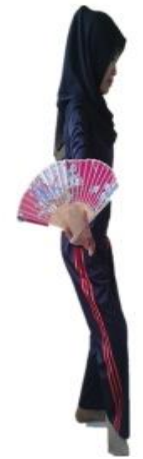

2

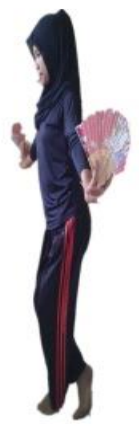

6

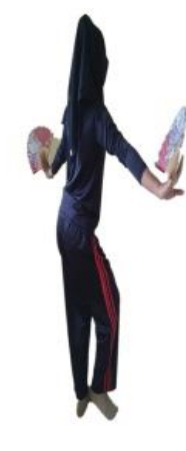

3

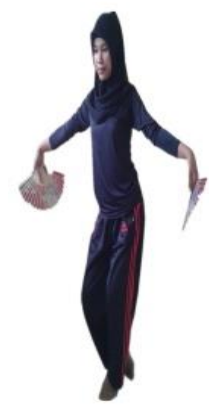

7

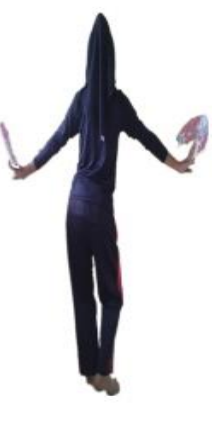

4

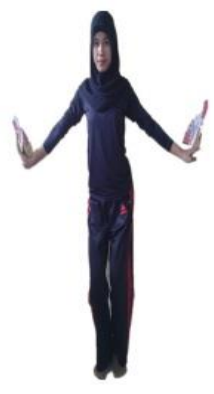

8

Gambar 4. Gerak timbangan

(Sumber: dokumen peneliti)

\section{Injak lado}

Gerak injak lado merupakan salah satu gerak yang juga terdapat dalam tari melinting. Injak lado merupakan gerak yang menggambarkan mata pencaharian masyarakat Lampung yang salah satunya adalah berkebun. Kebun yang menyebabkan Lampug juga dikenal dengan sebutan "tanoh lado". Gerak injak lado terdiri dari gerak kaki dan gerak tangan. Gerak kaki dilakukan bergantian, 
kaki kanan dan kaki kiri. Gerakan kaki dilakukan dengan cara menghentakkan salah satu sisi terlebih dahulu, kemudian diikuti dengan gerakkan berikutnya.

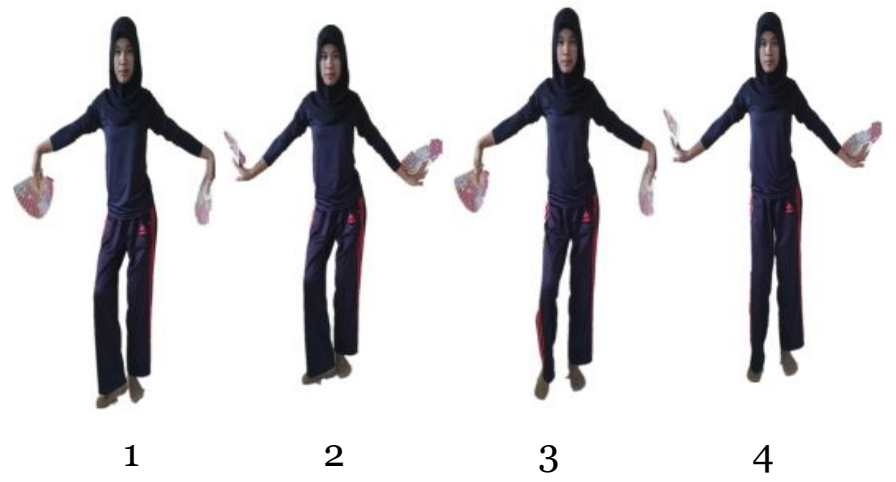

Gambar 5. Gerak injak lado

(Sumber: dokumen peneliti)

\section{Gerak lapah tebeng}

Gerak lapah tebeng merupakan gerak yang digunakan pada awal tarian saat penari memasuki area pentas. Gerak ini memiliki makna kemantapan hati seseorang dalam mengambil keputusan dan mencapai tujuan. Selain kemantapan hati, gerak ini juga merupakan gambaran harapan kepada Sang Pencipta agar senantiasa dibimbing pada jalan yang lurus.

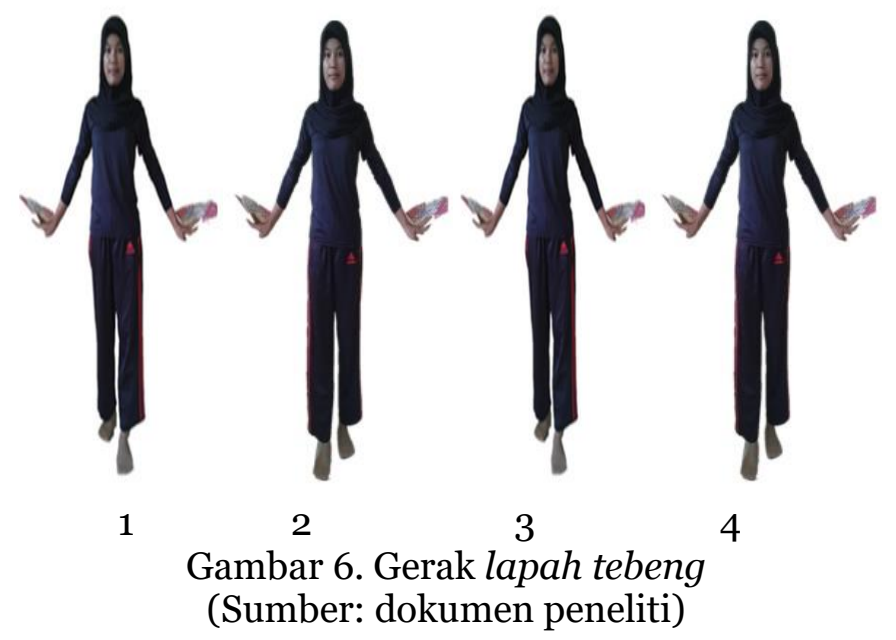

\section{Gerak sesayak}

Gerak sesayak merupakan salah satu gerak yang bisa dikatakan ciri dari tarian ini. Gerak sesayak merupakan gambaran gerak yang membelah sesuatu. Gerak sesayak dilakukan dalam berbagai level. Level sedang dan level tinggi. Macammacam level ini dalam kajian koreografi dinamakan pengulangan. Pengulangan tersebut memiliki arti bahwa ada hal yang ditekankan dalam gerak tersebut. Membelah merupakan salah satu kegiatan yang memerlukan keahlian yang baik agar tidak terluka. Salah satu keahlian yang digambarkan dalam tari yang menggambarkan kegiatan membelah adalah membelah bambu. Membelah 
bambu dalam gerak tari disebut belah huwi. Kegiatan ini merupakan salah satu keahlian yang juga terkait dengan mata pencaharian seseorang.

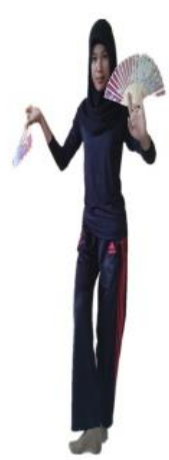

1

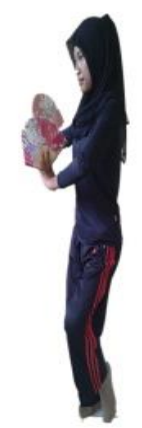

5

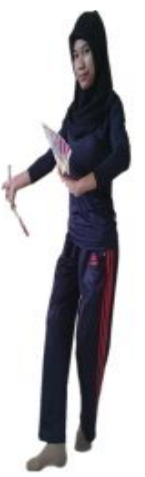

2

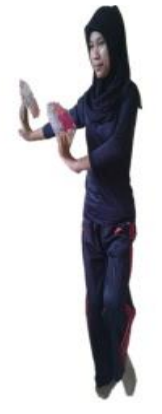

6

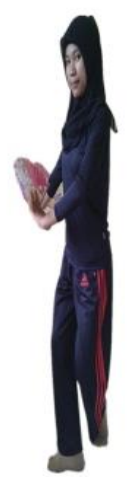

3

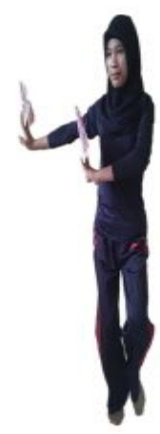

7

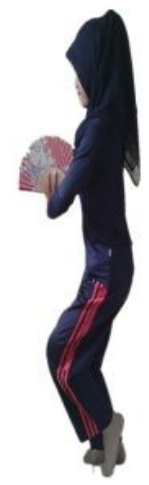

4

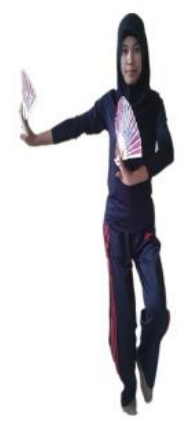

8

Gambar 7. Gerak sesayak

(Sumber: dokumen peneliti)

Koreografi tari halibambang, gerak Sesayak dapat dilakukan dengan cara berhadap-hadapan antar penari. Berikut ini adalah bentuk gerak Sesayak dalam garapan tari Halibambang. Gerak sesayak dilakukan dalam sebuah desain lantai trapesium. Desain lantai trapesium yang terdiri dari empat orang penari putra putri. Desain ini juga merupakan salah satu simbol Penyanggo adat dalam masyarakat Saibatin (Habsary, 2017). Simbol lainnya adalah warna kostum yang menunjukkan wilayah adat yaitu Saibatin. Tarian in merujuk pada tari nyambai yang berasal dari adat Saibatin. Namun saat ini tarian ini sudah menyebar hingga ke wilayah Bandar Lampung.

\section{Kesimpulan}

Tari halibambang merupakan tari yang menggambarkan kehidupan atau perilaku kupu-kupu. Hal ini dapat dilihat dari arti kata halibambang. Hal ini jika diartikan dalam bahasa Indonesia adalah seperti, kata bambang jika diartikan dalam bahasa Indonesia adalah kupu-kupu. Dengan demikian halibambang memiliki arti seperti kupu-kupu. Kupu-kupu diwakilkan dengan properti tari 
yaitu kipas. Kipas yang bermotif bunga-bunga menunjukkan lingkungan hidup dari kupu-kupu.

Makna yang dapat dikaji selain dari nama tarian adalah gerak-gerak yang terdapat dalam tarian. Gerak-gerak yang terdapat pada tari halibambang juga dapat ditemui dibeberapa tarian daerah Lampung lainnya. Gerak-gerak tersebut antara lain adalah lapah tebeng, tolak tebeng dan ghubuh gakhang. Gerak-gerak tersebut memiliki gambaran perilaku dan kegiatan sehari-hari masyarakat Lampung.

Selain menggambarkan perilaku masyarakat Lampung, gerak yang terkandung dalam tarian juga menggambarkan mata pencaharian masyarakat Saibatin. Mata pencaharian tersebut terkait erat juga dengan wilayah pemukiman masyarakat pendukung keseniannya. Gambaran-gambaran diatas juga dapat mengerucut pada nilai-nilai yang dianut masyarakat Saibatin dalam menjalin dan menjaga hubungan sosial. Aturan-aturan dan ketentuan yang harus dijaga dalam bersosialisasi. Seluruhnya bersumber kepada konsep piil pesenggiri (lihat: Hadikusuma, 1990).

\section{Referensi}

Azzahrah, F. (2017). Revitalisasi tari sigeh penguten melalui pendidikan seni budaya di smp negeri 1 Tanjung Raya kabupaten Mesuji. Catharsis: Journal of Arts Education, 6(1), 38-48.

Cassirer, E. (1944). An essay on man: An introduction to a philosophy of human culture. United States of America: Yale University Press.

Endraswara, S. (2003). Metode penelitian kebudayaan. Yogyakarta: Gadjah Mada University Press.

Habsary, D. (2017). Genre tari persembahan sebagai identitas budaya masyarakat Lampung (Disertasi). Institut Seni Indonesia Yogyakarta, Yogyakarta.

Hadikusuma, H. (1990). Masyarakat dan adat budaya Lampung. Bandung: Mandar Maju.

Hidayatullah, R., \& Bulan, I. (2017). Transformasi tari bedana tradisi menjadi tari bedana kreasi. AKSARA: Jurnal Bahasa Dan Sastra, 18(2).

Retrieved 28 February 2021 from http://jurnal.fkip.unila.ac.id/index.php/aksara/article/view/14774

Jazuli, M. (2001). Metode penelitian kualitatif. Semarang: Universitas Negeri Semarang.

Kusumawardani, I. (2013). Makna simbolik tari sontoloyo giyanti Kabupaten Wonosobo. Jurnal Seni Tari, 2(1), 1-8.

Miles, M. B., \& Huberman, A. M. (1994). Qualitative data analysis: An expanded sourcebook (2nd ed.). Thousand Oaks, CA: Sage Publications, Inc.

Moleong, L. J. (2017). Metodologi penelitian kualitatif (36th ed.). Bandung: PT. Remaja Rodakarya. 
Narawati, T. (2013). Etnokoreologi : Pengkajian tari etnis \& kegunaannya dalam pendidikan seni. International Conference on Languages and Arts, o(o), $70-74$.

Prabowo, A., Imron, A., \& Susanto, H. (2018). Simbol dan makna tari melinting pada masyarakat adat Lampung Saibatin di Desa Wana. PESAGI (Jurnal Pendidikan Dan Penelitian Sejarah), 6(4). Retrieved 2 March 2021 from http://jurnal.fkip.unila.ac.id/index.php/PES/article/view/17048

Rahmadona, I., Daryanti, F., \& Kurniawan, A. (2015). Pembelajaran tari kipas nyambai bebai menggunakan model kooperatif tipe STAD di SDN1 Waysindi, 3(2), 1-12.

White, L. (1949). The symbol: The origin and the basis of human behavior. In The science of culture: A study of man and civilization. United States of America: Far Straus \& Giroux, Inc.

Yustika, M., \& Bisri, M. H. (2017). Bentuk penyajian tari bedana di sanggar siakh budaya Desa Terbaya Kecamatan Kotaagung Kabupaten Tanggamus Lampung, 10. 